\title{
TEZCATLIPOCA/HADES: DOS COLUMNAS MÍTICAS CON UN BASAMENTO COMÚN
}

\author{
Kattia Chinchilla Sánchez
}

\begin{abstract}
RESUMEN
En este artículo se muestra la naturaleza mítica de dos dioses diferentes: Tezcatlipoca, del panteón azteca, y Hades, el dios del lugar de las almas oscuras. Ambas deidades tienen una base común: los atributos selénicos y solares. Más que una simple mitología comparativa, este estudio es un análisis serio de los patrones míticos y simbólicos de esas culturas disímiles. En los ritos, el homo religiosus demuestra horror hacia estos dioses ya que, según la regla coincidentia oppositorum, estos denotan el poder del mundo de la oscuridad.
\end{abstract}

\begin{abstract}
This article shows the mythic nature of two different gods: Tezcatlipoca, in the Aztec pantheon, and Hades, the Greek goddess of the dark soul's place. Both deities have a common base: the selenic and the solar attributes. This approach involves more than "comparative mythology". It is a serious study of the mythic-symbolic patterns of those dissimilar cultures. In the rites, the homo religiosus denotes his horror to those goddesses, because, follow to the coincidentia oppositorum rule, they shows the power of the world of darknes.
\end{abstract}

Desde tiempo inmensidad ha habido hombres y mujeres, los brujos profesionales, que se han lucrado de la ingenuidad de quienes creen en hechicerías.

Teodoro Vidal

\section{Introducción}

La guerra entre el bien y el mal es un motivo común en la historia de la humanidad y, por su parte, una premisa mítica universal. Uno de los mitos básicos y célebres de los aztecas es la Guerra Santa: creación del mundo en cinco soles, guerra alternativa entre Quetzacóatl y Tezcatlipoca, sucesión de la creación y la destrucción, disyuntiva entre la vida y la muerte. En términos simples, la Guerra Santa se da siempre entre el día y la noche, el cielo diurno y el cielo nocturno, el supramundo y el inframundo. El día, en virtud de la luz, ordena, separa los elementos, se identifica con el cosmos. La noche los confunde y es una imagen material del caos. 
Destrucción, inframundo, tinieblas, noche, magia, transformación... Características negativas atribuidas al dios Tezcatlipoca, a quien vamos a comparar con la deidad griega Hades. Para nosotros, estas figuras constituyen una tríada selénica: tinieblas, noche, el norte, el invierno, generalmente símbolo nefasto, el ojo malo de la deidad uránica. Empero, por ser la luna un astro celeste, hay un nexo entre el sol y el cielo: las tres imágenes mitológicas son omniscientes, ubicuas e intangibles.

El sol tiene un lado visible y positivo, pero también uno invisible y negativo: su paso diario por el mundo de las tinieblas, por el reino de la muerte.

Tezcatlipoca es el Enemigo, el Adversario guerrero, al igual que Satán, contendiente de Dios, como Tezcatlipoca lo es de Quetzalcóatl, cuya eterna lucha desencadenará, en el momento postrero, el fin del mundo. Como jaguar uno y dragón otro, son monstruos amenazadores o figuras del espíritu del mal. Para los cátaros (sectas herejes de los siglos XI y XII), Satanás es el demiurgo, creador del mundo, igual que Tezcatlipoca, un creador en el mito de los soles aztecas. Creador-destructor, he aquí la dualidad que caracteriza a los seres mitológicos, como hierofanías solares y selénicas a la vez.

Hades es príncipe de las tinieblas, símbolo de las profundidades. Es un amo despiadado, que no permite a ninguno de sus súbditos volver a la tierra. Este rasgo sanguinario es común para los tres personajes. Su nombre significa "el invisible" y era raramente mencionado, pues de hacerlo se temía excitar su cólera. Tezcatlipoca era el dios más temido del panteón azteca y ni hablar del terror que perturbaba a los medievales, un influjo satánico. Plutón era el epíteto de Hades, "el Rico", aludiendo a las riquezas inagotables de la tierra. Tezcatlipoca prodigaba tanto males como opulencias, al igual que Satanás.

Así pues, mediante este estudio, pretendemos hacer una homologación entre estos seres mitológicos y comprobar así que son verdaderas potencias oscuras basadas en los poderes selénicos y solares. Además, siempre notamos la coincidencia de los opuestos, o sea, la reunión de atributos contrarios que definen al ser mítico. Inclusive lo solar y lo selénico son contrarios de por sí, pero comparten una serie de rasgos que, en este caso, se identifican con lo oscuro y lo tenebroso.

\section{Tezcatlipoca, el dios de las discordias}

\subsection{Nacimiento de Tezcatlipoca}

Entre los aztecas hay una pareja primordial: Ometecuhtli y Omecíhualy (Tonacatecuhtli y Tonacacíhual), el Señor y la Señora de la dualidad, el Señor y la Señora de la subsistencia. Tienen cuatro hijos: Tezcatlipoca negro, Tezcatlipoca rojo, Quetzalcóatl y Huitzilopochtli (Tezcatlipoca azul). La pareja original y creadora tiene un culto restringido, están entre los dioses menos adorados. Perdieron su importancia hacia el siglo XIII, en el momento en que se implantó la dominación nahuatl.

Una de las versiones sobre el origen de Tezcatlipoca es ésta: los dioses astrales, al oír que su madre estaba embarazada, se sintieron irritados y tramaron la destrucción del nuevo ser. Fueron tenidos a distancia en una cueva, hasta el momento del nacimiento de la criatura, Tezcatlipoca, que surgió del seno materno como un guerrero con todas sus armas (de manera 
similar a la Atenea helénica), destruyó a sus enemigos y también a la única que le había ayudado, su hermana Coyolxauhqui ("Campanillas de oro"). Al no poder salvarla, le cortó la cabeza y la lanzó al cielo, donde ahora vive como luna (es una especie de catasterismo). En este ciclo de Tezcatlipoca, el dios es el sol, que adopta cuatro formas: amarillo (este), azul (sur), rojo (oeste) y negro (norte), siendo esta última la que lo distingue. Siguiendo una interpretación de tipo simplista, se trataría de un mito cosmológico que explicita el hecho de que la luna puede brillar incluso durante el día, mientras que las estrellas desaparecen al salir el sol. Las cuatro formas son los colores del cielo cuando el astro recorre cada uno de los sectores. Este relato tenía una expresión ritual en el sacrificio de un pájaro de plumas negras moteadas de blanco, para simbolizar la muerte de las estrellas en el alba.

Una de las ideas fundamentales de la religión azteca consiste en agrupar a todos los seres según los puntos cardinales y la dirección central, o de abajo arriba. Por eso en la mentalidad mexicana son tan importantes los números cuatro y cinco, como en la mágica occidental es el número tres.

Los cuatro hijos de la pareja divina (que representa la dirección central, arriba y abajo, es decir, el cielo y la tierra) son los regentes de las cuatro direcciones o puntos cardinales; por eso vemos que tres de ellos se nos presentan con colores diferentes: rojo, negro y azul, que corresponden al este, norte y sur, mientras que Quetzacóatl podría ser el primitivo Tezcatlipoca blanco, que representa el oeste.

\subsection{Los dioses creadores y antagónicos: Quetzalcóatl y Tezcatlipoca}

Dos son los dioses quienes alternativamente han creado las diversas humanidades que han existido: Quetzalcóatl, es dios benéfico, héroe descubridor de la agricultura y de la industria, y el negro Tezcatlipoca, el dios todopoderoso, multiforme y ubicuo, patrono de los hechiceros y de los malvados. Los dos dioses combaten y su lucha es la historia del universo.

A la creación en cinco soles se le llama Guerra Santa, porque es la guerra que tuvieron ambas divinidades. Su batalla es la consecución de la destrucción y la creación, que se suceden constantemente.

Primer Sol: Tezcatlipoca nocturno, el que tiene por nahual o disfraz al tigre, cuya piel manchada semeja el cielo, empezó la era del mundo inicial. Los primeros hombres eran gigantes, no cultivaban la tierra, sino que comían bellotas y otras frutas silvestres. Tezcatlipoca era también la constelación de la Osa Mayor, que para los aztecas era un tigre. Su enemigo Quetzalcóatl le dio un golpe con un bastón y cayó al agua, donde se transformó en ese felino y se comió a los gigantes. La tierra quedó despoblada y sin sol en el universo (Día 4 tigre).

Segundo Sol: Quetzalcóatl hizo el sol, hasta que el tigre Tezcatlipoca lo derribó de un zarpazo. Se levantó un gran viento y todos los árboles fueron derribados, la mayor parte de los hombres perecieron y los otros quedaron convertidos en monos (Día 4 viento).

Tercer Sol: Los dioses creadores pusieron por sol al dios de la lluvia y el fuego celeste, Tláloc, pero Quetzalcóatl hizo que lloviera fuego y los hombres murieron o quedaron convertidos en pájaros (Día 4 lluvia). 
Cuarto Sol: Quetzalcóatl puso por sol a la hermana del Tláloc, la diosa Chalchiuhtlicue, "la de faldas de jades", diosa del agua. Fue Tezcatlipoca quien hizo que lloviera con tal fuerza, que la tierra se inundó, los hombres perecieron y fueron transformados en peces (Día 4 agua). El cielo, que es agua, cayó y hubo que levantarlo para reiniciar la creación.

Quinto Sol: es el actual y será destruido por los terremotos en el Día 4 temblor.

Quetzalcóatl es el arquetipo de la santidad; su vida de ayuno y penitencia, su carácter sacerdotal, su benevolencia con sus hijos, los hombres, son patentes a través de las diferentes crónicas. Pero hay un lado oscuro: Quetzalcóatl cae en el pecado, que se traduce en la violación de la abstinencia sexual y la caída en la embriaguez, esto por el influjo maléfico de Tezcatlipoca. Tal es la lucha o rivalidad entre los dioses:

La religión del Anahuac, del México central, presenta, pues, cierto número de caracteres muy particulares; imposible definirlos todos: un politeísmo fundamental e ilimitado, una concepción de la historia y del mundo en términos de lucha, el combate entre las fuerzas masculinas y femeninas, de Tezcatlipoca y Quetzalcóatl, de las potencias nocturnas, contra las diurnas, del sol contra la luna y las estrellas, del bien contra el mal... (Mitologías... 1967: 188)

El destino de los hombres depende de la voluntad divina, pero, más aún, del orden del universo. La subida, el ocaso y el retorno del Sol simbolizan la muerte y el renacimiento de todas las cosas, como la aparición y luego crecimiento y desaparición de la luna -nacimiento, juventud, vejez- simbolizan la periodicidad sin fin, el ritmo vital. La tribu, queriendo ser triunfadora sin cesar, se asimiló al sol victorioso. Los aztecas han sido llamados el pueblo del sol. La historia del astro rey, de su combate contra las potencias nocturnas, es la historia divina y el arquetipo de la aventura humana. Quetzalcóatl, dios civilizador, hubo de sufrir un terrible combate contra Tezcatlipoca, dios nocturno por excelencia. Igualmente, el Quetzalcóatl "histórico", rey-sacerdote de Tula, héroe mítico, fue expulsado de su ciudad por el clero de Tezcatlipoca, dios que producía más horror que ningún otro, por lo que mereció la supremacía (no política pero sí religiosa). El juego de pelota, rito importante en todo México, es la representación dramática de esa costumbre.

Tezcatlipoca expulsa a Quetzalcóatl de Tula, capital de los toltecas, gracias a sus artes mágicas. El dios llevó a la ruina a la próspera ciudad. Se cuenta allí el siguiente mito: Tezcatlipoca se disfraza de huaxteco, es decir, que aparece desnudo como andaban los hombres de ese lugar y vende chiles. La hija de Huémac lo ve y se enferma de deseo. Su padre lo manda a traer y entonces lo casa con ella, esto causa problemas a Huémac, que lo llevan a perder el trono.

\subsection{Características}

(...) era tenido por verdadero e invisible, el cual andaba en todo lugar, en el cielo, en la tierra y en el infierno (...) y decían él solo ser el que entendía en el regimiento del mundo, y que él solo daba prosperidades y las riquezas y que él solo las quitaba cuando se le antojaba (Sahagún 1956: 50).

Es un dios creador, como vimos. Su nombre significa espejo humeante (adivinatorio), aunque originalmente es el cielo nocturno y está conectado por eso con todos los dioses 
estelares, con la luna y con aquellos que implican la muerte, maldad o destrucción. Es patrono de los hechiceros y de los salteadores (este último rasgo, propio del dios griego Hermes). Como Mago y Transformador (característica lunar) es capaz de llevar a cabo las más horribles crueldades. En una de sus manos está colgado el catalejo con el que ve a la gente, al pasado, al presente y al futuro. Como transformador, es identificado con el cielo y todos sus alimentos, doble en todas las cosas (de ahí la doble flecha, en el calendario azteca): día y noche, vida y muerte, lo bueno y lo malo (coincidencia de los opuestos). El cruce de los caminos era marcado con un asiento para Tezcatlipoca, el dios que atraviesa todos los caminos (como en la antigua Grecia sucedía con el dios Hermes y sus hermata). Pero al mismo tiempo es eternamente joven, el Telpochtli, el que no envejece nunca, y Yáotl, el enemigo, el patrono de los guerreros, por lo que se encuentra conectado con Huitzilopochtli (Tezcatlipoca azul).

Este dios era principalmente el de la providencia, y estaba en todas partes y entendía de todos los asuntos humanos, por lo que era adorado no sólo en Tenochtitlán, sino en otras partes de México, especialmente en Texcoco.

Al contrario de Huitzilopochtli, el cielo azul, Tezcatlipoca representaba el cielo nocturno. Es el guerrero del norte, mientras que el otro lo es del sur.

Es también el inventor del fuego, aunque este elemento tiene por patrono especial al dios Xiuhtecuhtli, el señor del año, también llamado Huehuetéotl, el dios viejo.

Es patrono de los príncipes y él mismo recibe el nombre de Nezahualpilli, el príncipe que ayuna y, con el nombre calendárico de Ome Acatl (la doble flecha), preside en los convites y banquetes.

Es el señor del frío y del hielo (esto por su relación con el norte), con el nombre de Iztlacoliuhqui, el cuchillo corvo de pedernal. Es también el dios del pecado y de la miseria (rasgo propio de Satanás). Los pecadores lo invocan en sus confesiones. Como Yaolli Ehecalt, el viento del norte, vaga en busca de hacedores malignos.

Preside la casa de los guerreros mozos y solteros, en la escuela popular de guerra a la que asisten los jóvenes plebeyos (Quetzalcóatl es el patrón de la escuela de los nobles, de donde salen los jefes superiores del ejército, los sacerdotes, los jueces y los reyes).

Rapta a la esposa del viejo Tláloc, a la diosa de las flores y del amor, Xochiquetzal (lo cual se asemeja al rapto de Perséfone por parte de Hades).

En sí mismo es invisible e impalpable (como Hades y Satanás, pues residen en el mundo inferior), penetra todas las cosas. Si se le aparece al hombre, se ve como una sombra en fuga. Puede asumir múltiples formas monstruosas (como el Demonio cristiano) para tentar o probar al hombre, transmitiéndoles una enfermedad o la misma muerte.

Pues es un dios nocturno es también negro, pero su rostro lleva una pintura facial con rayas horizontales amarillas y negras. Esta pintura se llama ixtlán tlatlaan y caracteriza a todos los Tezcatlipocas, al variar en su color.

Su pelo está cortado en dos alturas diferentes (tzotzocolli), característico de los guerreros. Lleva el aztaxelli o adorno de plumas de garza, el escudo o chimalli, los lanzadardos o atlatl y dardos (tlacochtli), que lo caracterizan.

En los códices, aparece pintado de negro y su cabeza está coronada del plumas de codorniz. Entre sus epítetos figuran: Nevoc Yaotl: sembrador de discordia; Moyocoyatzin: hace lo que le place, el que puede de hacer morir, destruir el cielo y la tierra y acarrear el fin de los 
vivos; Telpochtli: el mancebo (aludiendo a su estado de eterna juventud); Yoalli Ehécatl: viento nocturno (frío, como el Bóreas, el Favonio o el Céfiro de los griegos); Titlacaua: "cuyos hombres somos"; Moyocoyani: el que se inventa a sí mismo.

Tezcatlipoca es el "anti-sol", el dios de la noche y de las potencias malignas que ésta libera, el dios de la Oscuridad, del Sol vencido y las tinieblas victoriosas.

\subsection{Emblemas y atributos}

Sus emblemas incluyen la serpiente de fuego, símbolo de los fuegos celestes. El es Iztli-Tezcatlipoca o Técpatl, el dios del cuchillo de piedra (obsidiana), del mundo infernal, de la penitencia, de la sangre y el sacrificio humano. Sahagún dice que él levanta las guerras, a los enemigos y las discordias (Necoc Yaotl: sembrador de discordias por ambas partes donde quiera que vaya, como ya vimos). Este rasgo puede apreciarse en el dios griego Ares y la diosa Eris. No obstante, él es el rector del mundo, de él proceden todas las prosperidades y riquezas (coincidencia de los opuestos). Frecuentemente es representado como un jaguar, el dragón del eclipse, un ser transformado en bestia. El jaguar, que es el corazón del monte (Tepeyolohtli), es su disfraz. Simbolizaba la tierra y era el animal totémico del dios. El animal devoraba el sol; era el demonio de la oscuridad nocturna: las manchas de su piel inducían a una comparación con las estrellas del cielo. Otro animal totémico es el pavo: símbolo del sol exilado de la tierra, es decir, una encarnación del águila caída (el atardecer) para ser sustituida por el jaguar (la noche) como símbolo de las profundidades subterráneas. A continuación hablaremos detalladamente de cada uno de los emblemas y atributos.

El cuchillo, como todos los instrumentos cortantes, implica un principio activo, por su aspecto fálico, también relacionado con la serpiente, como se ve en la novela Bodas de sangre de Federico García Lorca. En muchas culturas, como la mexicana, maya e inca, el cuchillo se atribuye a las divinidades terribles, como arma cruel. Es un emblema lunar por tener una curvatura. He aquí un rasgo lunar en el dios azteca que nos ocupa. Es un instrumento propio de los sacrificios, que se le otorgan efectivamente a Tezcatlipoca. El cuchillo destruye, corta, interrumpe, características autóctonas del dios, asociado con las ideas de venganza y muerte, que comparte con Hades y Satanás. En psicología, representa las fuerzas instintivas del hombre.

El cuchillo de Tezcatlipoca generalmente se representa hecho de obsidiana. Itztli es una piedra vitrosa comúnmente de color negro, de la que se obtenían flechas y navajas; por su gran filo, tenía un valor incalculable, tanto para la cacería como para otros menesteres, de ahí su gran importancia ritual.

En el pensamiento mexicano, la obsidiana se emparenta con el frío, la noche, el país de la muerte y el norte, ideas afines al dios. En algunas versiones, se dice que la deidad tenía un cuchillo de obsidiana en lugar de pie. El espejo adivinatorio de Tezcatlipoca fue hecho de este material.

El jaguar es sobre todo una divinidad ctónica (subterránea), expresión de las fuerzas internas de la tierra: señor de lo que está abajo (al igual que Hades y Satanás), reviste a veces una función de psicopompo. Se le ha asociado al poder político, a los poderes ocultos de los 
magos y de los hechiceros, así como al mundo nocturno y subterráneo, a las cuevas, a las fuentes, a la oscuridad y a la noche.

Este felino tiene también un simbolismo uránico: devora al sol y a la luna. Ambas acepciones, una ctónica y otra uránica, son complementarias, aunándose las fuerzas de arriba con las de abajo para operar, en última instancia, la destrucción final del mundo. Es una hierofanía solar en su curso nocturno: el sol negro, con características ctónicas, pues el astro ya no es manifiesto, es virtual cuando atraviesa las regiones infernales y oscuras.

El tigre, animal similar al jaguar, evoca las ideas de potencia y de ferocidad. Es un animal cazador, y por ello símbolo de la casta guerrera, la que representa Tezcatlipoca. Monstruo de la oscuridad y de la luna.

El pavo es también disfraz de Tezcatlipoca. Símbolo doble, de potencia viril y de fecundidad maternal. Cuando hincha su cuello, el pavo evoca la erección fálica. Representa la arrogancia y el orgullo del macho, al contonearse tal vez ridículamente ante la hembra. Como nota curiosa, hay un proverbio inglés que data de 1520 y dice: "Turkey, carps, hops, pickerel and beer, came to England all in one year."

Uno de sus atributos o emblemas es el tlachialoni o itlachiayan, una especie de disco de oro, pulido como un espejo y horadado, llamado por los españoles, el catalejo o anteojo de larga vista. Se creía que por su agujero, Tezcatlipoca podía ver la tierra y los corazones de los hombres (rasgo de omnisciencia). Al portar este objeto, se le llamaba "aquel de la figura amarilla", epíteto que manifiesta un vínculo solar, por su color.

El espejo humeante es su más conspicuo emblema, un espejo cuya espiral de humo es, algunas veces, representada en forma ascendente. Ya anotamos como su mismo nombre hace alusión a este respecto; según Pomar, su ídolo estaba pintado con un tizne de reflejos metálicos que los indios llamaban texcapoctli o humo espejeante. Como ya hemos señalado, puede ver todo lo que está en la tierra, en el cielo y en el infierno, lo que revela un rasgo propio de las deidades uránico-solares.

En un poema consagrado a él y recopilado por Hernado Ruiz de Alarcón, en la primera mitad del siglo XVII, se hacen alusiones a sus características esenciales y representativas: ser el enemigo, el color negro y tener un espejo mágico; he aquí la versión de Angel Ma Garibay:

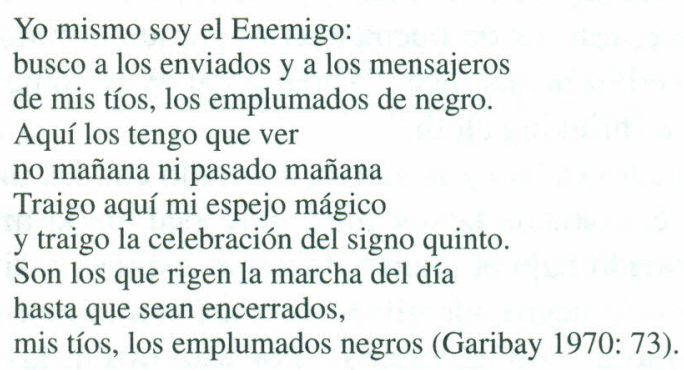

Este espejo reemplaza su pie (o un cuchillo de obsidiana) (la pérdida o anormalidad de un pie es común es el panteón mexicano, rasgo selénico, amén de sus faces) porque las puertas del mundo inferior se cerraron prematuramente sobre él. Otra versión registra un relato diferente. En su lucha con la tierra madre de las aguas de la creación (Tlaltecuhtli), que adoptaba la forma de un caimán gigantesco (Cipactli), el dios perdió el pie izquierdo, de forma 
que ya no pudo sumergirse de nuevo en el océano primordial, que se convierte en la tierra, cuyas montañas son las crestas de su piel de reptil.

Del latín speculum, originariamente la acepción "especular" respondía a observar el cielo y los movimientos de las estrellas, con la ayuda de un espejo. El espejo refleja la verdad, la sinceridad, el contenido del corazón y de la conciencia, evidencia el presente, pasado y futuro. Por tanto, Tezcatlipoca es un dios omnisciente. Su uso en las artes adivinatorias ratifica su ligamen con la práctica y presidencia de la magia. Al reflejar la luz o la imagen, acto pasivo, el espejo se revela como hierofanía lunar.

El humo es la imagen de las relaciones entre la tierra y el cielo. Esto reafirma el conocimiento de Tezcatlipoca sobre las cosas de la tierra, pues como deidad solar, no visible, como tutor de las tinieblas, al descender a las profundidades de la tierra se establece tal ligamen. La columna de humo es análoga al axis mundi, al lazo de unión entre ambas regiones, la superior y la inferior. El humo, por su naturaleza, evoca al mundo de las tinieblas y las sombras. Por ejemplo, en el culto católico, durante las exequias fúnebres, el sacerdote libera incienso (humo) ante el ataúd del cristiano fallecido.

En Tezcatlipoca notamos una relación muy fuerte entre el norte, lo negro y la noche. Los mexicanos asociaban al norte con los muertos, con los antepasados y con las tribus cazadoras. Los zapotecos, lo relacionan con el color negro, con las miserias y las desventuras.

Según el libro del Bahir, el mal reside en el norte y Satanás, en cuanto a principio de seducción, principio del mal, viene justamente de ahí. En Jeremías (46, 20), leemos: “el destructor viene del septentrión". El viento del norte se considera devastador y, asimismo, fecundador y creador. La destrucción y el mal son rasgos comunes de Tezcatlipoca y Satanás. El norte es también el país de la luna, por lo que vemos un matiz selénico en el dios azteca, cuyo color es el negro y las tres figuras están atadas a la zona ctónica o infernal. Este lugar es cambiante, pues allí radica el enigma de la vida y la muerte; por tanto, lo ctónico se asimila con la luna, la cual cambia y conjuga la vida y la muerte en sus consecuentes fases.

Al estar relacionado con el norte, con la oscuridad, como sol caído o anti-sol, el astro rey no brilla desde el norte. En el contexto bíblico, como ya veíamos, el norte es el lugar del diablo, como lo vemos en Isaías 14,12, donde se afirma que allí nace el orgullo de Lucifer y los descreídos. En el folklore es la región de la muerte, si la cabeza de la madre está colocada hacia el norte cuando el niño nace, esto es de buena suerte, porque el niño nacerá hacia el sur que representa la vida. Un proverbio inglés dice: "Three great evils come out of the North, a cold wind, a cunning knave and a shrinking cloth."

Por su aspecto, el negro es frío y negativo, asociado con las tinieblas primordiales, con la indiferencia original, es el color de la sustancia universal, de la materia prima. El norte es negro para los aztecas. Instalado bajo el mundo, lo negro expresa pasividad absoluta, el estado de la muerte (Hades es llamado negro, identificándolo así con lo mortuorio). Negra es la tierra fértil, receptáculo de la semilla y de las tumbas. Por esta razón, las ceremonias de culto de Plutón comprendían sacrificios de animales negros y la cabeza de la víctima debía estar vuelta hacia la tierra. La oscuridad de los orígenes precede a la creación en todas las religiones: la nada, el caos, la confusión y el desorden.

Bien podemos mencionar ahora el aparato ritual hacia Tezcatlipoca, a partir de las oraciones de sus fieles, quienes por temor a él lo evocaban en "plegarias", las cuales no deben 
mal interpretarse, pues su poder era tan grande que son los gobernantes o reyes los que recurrían a ellas. Veamos los textos.

\title{
Plegaria a Tezcatlipoca para los tiempos de plaga
}

\begin{abstract}
¡Oh poderoso Señor, bajo cuyas alas buscamos protección y amparo! Tú, arte invisible, impalpable, como el aire y como la noche. Yo vengo con humildad y pequeñez, atreviéndome a aparecer ante tu majestad. Yo vengo expresando mis palabras como el que se ahoga y tartamudea; mi discurso es un viaje como el camino de aquél que extravía la senda y tropieza. Yo estoy poseído por el miedo de tu excitante ira contra mí más que el deseo de merecer tu gracia. Pero, Señor, haz con mi cuerpo lo que te plazca, porque verdaderamente nos has abandonado de acuerdo con tus consejos, tomados en el cielo y en el infierno. ;Oh dolor!, tu ira y tu indignación han descendido sobre nosotros durante todos nuestros días.
\end{abstract}

¡Oh Señor, muy piadoso! Tú sabes que nosotros los mortales somos como niños que, cuando son castigados, lloran y suspiran, arrepentidos de sus faltas. Esto es igual: estos hombres, arruinados por tus castigos, se reprochan a sí mismos dolorosamente. Ellos se confiesan en tu presencia; ellos expían sus malas acciones, imponiéndose su propia penitencia. ¡Señor, muy bueno, muy compasivo, muy noble, muy hermoso! deja el castigo que les has inflingido ya suficiente, y deja a los enfermos, a quienes les has mandado castigo, para que encuentren su fin (Mythology of ... 1964: 63) (La traducción es nuestra).

\section{Oración al rey coronado}

Tal vez, juzgándose a sí mismo pésimo para esta alta ocupación, él pensaría perpetuarse en eso. ¿Esto no deseará ser para él un sueño de pesar? ¿El encontraría en esta dignidad, recibida de tus manos, una ocasión de orgullo y presunción, hasta que esto acontezca, él desprecia el mundo, asumiéndose a sí mismo como espectáculo suntuoso? Tú, Majestad, conoces bien a qué fin él está obligado a llegar en pocos días -porque nosotros los hombres estamos para tu diversión, tu teatro, que sirve para tu risa y entretenimiento (Mythology of... 1964: 63) (La traducción es nuestra).

Oración al rey muerto

Tú le has dado por probar en este mundo lo poco de tus dulzuras y suavidades, haciéndolas pasar ante tus ojos como el deseo de fuego fatuo, que se desvanece en un instante; así es la dignidad del pilar donde tú le diste lugar, y en el cual él se ha postrado por pocos días, con lágrimas, exhalando sus devotas oraciones para tu majestad. Tú, arte invisible e impalpable, nosotros creemos que tu mirada fija hace penetrar las piedras y en los corazones de los árboles, viendo claramente todo lo que está oculto adentro. Así, haz tu mirada y comprende lo que está en nuestros corazones; delante de ti nuestras almas son como una fluctuación de humo o como un vapor que se levanta de la tierra (Mythology of... 1964: 64) (La traducción es nuestra).

Atendiendo al mensaje de las oraciones, la relación nietzchana del do ut des está dada entre la deidad y el creyente. De allí la gran cantidad de sacrificios humanos, instalados en un marco netamente mítico-ritual, como el siguiente.

Se realizaba en primavera, cerca de la Pascua de Resurrección, dice Sahagún. En el año previo un joven ha sido seleccionado de un grupo de cautivos traídos para tal propósito: físicamente, el candidato no debe tener manchas y debe poseer todos los talentos posibles. El elegido era entrenado para cantar y tocar la flauta, acarrear flores y fumar con elegancia; era vestido con bellos ropajes y acompañado constantemente por ocho pajes. El rey mismo suministraba su ropa de vestir. Cuando se acercaba el año, este joven era agasajado por el 
pueblo, que le ofrecía banquetes. La gente pensaba que era una encarnación viviente de Tezcatlipoca. Veinte días antes del festival, su uniforme es cambiado y su largo cabello es ataviado a la usanza de los jefes aztecas. Cuatro doncellas le son asignadas como esposas, llamadas con la advocación de cuatro diosas: Xochiquetzal (pluma de quetzal que florece), Xilonen (joven maíz), Atlatonan (una diosa de la costa) y Uixtociuatl (diosa del agua salada). Durante los cinco días previos al sacrificio, comienza una serie de banquetes y danzas, que duran cuatro días. Así llega el día final, el joven es capturado, sus esposas-diosas lo abandonan. Es llevado a un pequeño templo a la orilla de un camino para la consumación del rito. El ascendía cuatro gradas, rompía una flauta en cada una, hasta que en la cumbre era asido por el sacerdote, quien, luego de abrir su pecho con un solo golpe, presentaba su corazón al sol. Inmediatamente, otro joven era escogido para el año entrante, con el objeto de que Tezcatlipoca nunca muriera.

El negro se vincula con la idea del mal y los tres personajes se identifican con estos dos rasgos. Así, en algunas escasas imágenes de la Edad Media de Judas, el traidor aparece vestido de negro. Los escolares ingleses llaman black monday al lunes, día de vuelta a clases, como algo negativo y los romanos señalaban con una piedra negra los días nefastos (de mala suerte). Satanás y Hades son los príncipes de las tinieblas. Las vestiduras negras están relacionadas tradicionalmente con el mal, como se ve en los trajes oscuros de los dictadores en El Señor Presidente y Amalia. Además, el rostro de Tezcatlipoca es negro.

En El Señor Presidente, Miguel Angel Asturias hace ver que en la composición de la obra hay huellas profundas de mitología precolombina. Amalia, de José Mármol, al igual que la novela anterior, contiene una figura dictatorial que se identifica con el "dios negro", maligno y tenebroso:

El lleva un calzón de paño negro (...) o un sombrero de paja cuyos largos bordes le cubren el rostro (Mármol 1980: 30).

El presidente lleva, como siempre, un luto riguroso: zapatos negros, traje negro, corbata negra, sombrero negro que no levanta jamás (Asturias 1984: 15).

El color negro es propio de Tezcatlipoca, como ya hemos visto, por tal razón su figura era tallada en obsidiana.

Veamos este otro contraste:

Nunca se sabe en qué sitio preciso se encuentra. Finge instalarse en un lugar para pasar allí la noche y media hora más tarde la estancia está vacía bajo la guardia de un soldado (...) El cambia de sitio a fin de que todo el mundo ignore dónde se halla (Mármol 1980: 35).

Se ignora su domicilio porque él vive en el exterior de la villa, en varias casas a la vez; duerme, pero se cuenta que está junto al teléfono con un látigo en la mano. Sus amigos aseguran que jamás muere (Asturias 1984: 23).

Aquí encontramos varias características de Tezcatlipoca: ubicuidad, omnipresencia y omnisciencia ("jamás duerme”). Como cosa curiosa, se cuenta que Stalin hacía el mismo ritual al dormir: había varias habitaciones, fuertemente construidas con acero, todas instaladas en una sola estancia. Al cerrar la puerta principal, Stalin era el único que escogía uno de los aposentos, así que sólo él sabía en dónde estaba.

El hombre negro, maestro todopoderoso de la vida y de la muerte de los hombres, omnipresente, invisible para el común de los mortales, este hombre negro es también un héroe 
romántico; pero más que una expresión política, finalmente secundaria, es la manifestación de una fuerza primitiva y mítica.

Carlos Fuentes, en Terra Nostra, hace del dios negro, el doble cojo del rubio y luminoso Quetzalcóatl. Aquí el autor mexicano interpreta la lucha de estos hermanos, enemigos y complementarios, como la metáfora de las fuerzas antagónicas que desgarran y enriquecen nuestra personalidad: la guerra entre el bien y el mal.

La plaza cayó después de una lucha feroz. Se lo comunicaron en el campamento: dentro de la siguiente hora estaba entrado a la ciudad vencida y en su memoria negra y brillante como corazas de los mercenarios alemanes de su ejército, turbia y líquida como las lagunas que rodeaban el burgo sitiado... (Fuentes 1992: 52).

La batalla, el combate a muerte entre dos seres cercanos no sólo presenta rasgos escatológicos sino también cosmogónicos; es esa cadena interminable de los ciclos cósmicos recurrentes: vida-muerte-renacimiento, sea luego de una guerra, sea luego del acto sexual, sea luego del fin natural del hombre o de la especie. Eliade (1984: 30-1) se refiere a los dayak -cultura de Borneo- para enunciar la función, el significado y el valor del paradigma de la creación, tal cual lo concibe Carlos Fuentes.

Para finalizar acotemos que la noche es rica en todas las virtualidades de la existencia. Entrar en la noche es volver a lo indeterminado, donde se mezclan las pesadillas, los ogros y los adefesios. Es la imagen de lo inconsciente: el mal se constituye en un "monstruo" interno por vencer. La propia noche, sin embargo, presenta un doble aspecto, el de las tinieblas donde se fermenta el devenir, y el de la preparación activa del nuevo día, de donde brotará la luz de la vida.

\section{Hades, el rey del mundo de los muertos}

\subsection{Características}

Hades es el dios de los muertos. Es hijo de Cronos y Rea, hermano de Zeus, Poseidón, Hestía, Hera y Deméter. Con Zeus y Poseidón es uno de los soberanos que se repartieron el imperio del universo, después de la victoria sobre los Titanes. Zeus obtuvo el cielo, Poseidón el mar y Hades el infierno, el mundo subterráneo.

Los Cíclopes lo armaron con un casco que volvía invisible al que lo llevaba. Este casco de Hades, semejante al de Sigfrido en la mitología germánica, fue usado por Atenea y Perseo.

Hades reina sobre los muertos. Es un amo despiadado, que no permite a ninguno de sus súbditos volver a la tierra, entre los vivos. Es asistido por demonios y genios múltiples (Caronte y Cerbero). Rapta a Perséfone, hija de Deméter, con lo que se introduce en el ciclo de Eleusis.

Hades significa invisible y era raramente mencionado. Se le designaba por medio de eufemismos: el buen consejero, el afamado, el hospitalario, el que cierra la puerta y el odioso.

Habita debajo de la tierra, en el Tártaro tenebroso y siempre privado de luz. Otorga a los vivos las riquezas de los años. Asentó su trono en las tinieblas. Manda sobre los hombres. 
Demonio de mil nombres, que tiene gran capacidad. Dueño único de las cosas conocidas y ocultas. Un himno órfico lo describe así:

Dios que gobiernas todo, sacratísimo, honradísimo, que disfrutas con las buenas alabanzas y con el culto piadoso, te suplico que seas propicio a los que para ti sacrifican (Himno órfico 18) (La traducción es nuestra).

Era un juez inflexible y los griegos lo representaban como un hombre de rostro majestuoso y feroz, gran barba y abundante cabellera. La barba es símbolo de virilidad, de coraje y de sabiduría. Es propio de los dioses solares, haciendo un parangón entre los rayos del sol y los pelos de la barba. El crecimiento de ésta se homologa con la fertilidad. Ya hemos visto cómo Hades se relaciona con la fecundidad. El crecimiento de la barba estaría regido por la luna, pues como si fuese vegetación surge desde una zona ctónica, la zona de Hades, hacia la superficie. Hay una relación contraria entre la barba y el muerto:

\section{(...) the living as opposed to the dead: in primitive frescoes only the living have beards, the dead none; this also applies to Christ who has a beard on earth, and is clean-shaven after his death (the un-sexing taking place after death) (Ad de Vries 1984: 39).}

En cuanto a los cabellos, representan muy frecuentemente ciertas virtudes o poderes masculinos: la fuerza y lo viril, como en el mito bíblico de Sansón. La cabellera suelta es a menudo una característica de las divinidades terribles (Gorgonas, Tifón). Dispuesta alrededor de la cabeza es una imagen de los rayos solares. En el pensamiento simbólico, los cabellos están ligados igualmente a la hierba, cabellera de la tierra y, por tanto, a la vegetación.

Se sentaba en un trono de ébano o azufre, sustancia que se vincula siempre con Satanás y el Infierno. En la mano derecha ostentaba un cetro, una vara para conducir las almas y un tridente, que algunas veces era de dos puntas.

En la villa Borghèse (Pompeya) aparece con una cabeza de lobo, una variante del Hades kyné: de piel de perro. El lobo es sinónimo del salvajismo, del desenfreno. Su simbolismo es dual: por un lado, feroz y satánico, y por otro, benéfico. Por ver en la oscuridad, se le asocia con la luz y, con ello, es un símbolo solar. El animal también se asocia con la fertilidad. En Anatolia, aún se aprecia a las mujeres estériles invocar al lobo para tener hijos. El lobo es un psicopompo: conduce las almas al reino de los muertos. En la mitología grecolatina se manifiesta como divinidad infernal: Hades se viste con piel de lobo.

Los lobos simbolizan la muerte cósmica: son devoradores de astros, lo cual evoca al jaguar azteca, que abre sus fauces monstruosas para tragar el sol. Aquí el matiz es lunar.

En la imaginería europea de la Edad Media, el lobo es la forma asumida por los brujos en el Sabbat. Aquí es símbolo del principio del mal, elemento destructivo del universo y del hombre.

No existe ninguna mitología que no haya asociado al perro con la muerte (Anubis, T'ien-K'uan, Cerbero, Xolotl, Garm), al mundo de los infiernos, a los imperios invisibles, regidos por las divinidades ctónicas o selénicas. Su primera función es de psicopompo, es guía del hombre en la noche de la muerte.

Como hierofanía lunar, es antepasado mítico de una etnia y un héroe civilizador. Símbolo de potencia sexual, por tanto, denota perennidad, desbordante de vitalidad como la naturaleza en primavera. 


\subsection{Epítetos}

Los epítetos homéricos expresan la brutalidad, su fuerza indomable y el terror que inspira a los mortales: ifthimos (Odisea X, 534; XI, 47): fuerte, poderoso; kráteros (Ilíada XIII, 415; Odisea XI, 277): vigoroso, fuerte, potente; pelóorios (Ilíada V, 395): prodigioso, monstruoso, gigantesco; stygerós (Odisea VIII, 368): odioso, abominable, horroroso, terrible; ameílijos (Odisea IX, 158): amargo, duro; adámastos: indómito, indomable, inexorable.

Homero dice que Hades es la más odiosa de todas las divinidades (Odisea IX, 159). Pero el dios infernal no siempre fue, para los hombres, objeto de espanto y terror, pues también se le consideraba el que presidía la producción agrícola. Hesíodo recomienda al campesino beocio ofrendar su labor al Zeus Ctonio, es decir, Hades. Empédocles iba más allá y llamaba a la tierra: Aidoneo nutricio.

Esquilo le atribuye a Hades el papel justiciero y vengador (Euménides, 269). Lo llama nekrodégmoon (Prometeo, 154): el que recibe a los muertos. Sófocles lo advoca pagkoítees (Antígona, 810): que todo lo adormece; mélas (Edipo Rey, 30): negro, oscuro, sombrío malvado, siniestro; énnyjos (Traquinias, 501): nocturno, que vive en la oscuridad; apótropos (Ajax, 608): fugitivo, odioso, abominable, que aparta los males; fónios (Edipo en Colono, 1688): cruento, sanguinario, mortífero, que mata.

La mayoría de los epítetos expresan el horror que provoca en el hombre la muerte, lo cual obedece a una tendencia instintiva que lo lleva a ocultar con eufemismos las ideas fúnebres: los griegos de Hermíone le dieron a Hades el nombre de Clímenos ("célebre", "famoso", según Pausanias 2, XXXV, 9).

El sobrenombre más corriente era Plutón, "el Rico", aludiendo a las riquezas inagotables de la tierra. Bajo esta denominación, es presentado sosteniendo el cuerno de la abundancia, símbolo de la riqueza.

Como Plutón es un dios benefactor y dispensador de la fecundidad agrícola. Se ha supuesto que su nombre proviene del culto de Eleusis, en el cual Hades, como esposo de Perséfone, está íntimamente relacionado con las grandes diosas de la agricultura. Así, Hades sería transformado en dios agrícola, por ello, el cuerno de la abundancia tiene un lugar de honor en el banquete de los dioses.

Para la astrología analítica, Plutón, el príncipe de las tinieblas, es el símbolo de las profundidades de nuestras tinieblas interiores que alcanzan la noche original del alma, es decir, las capas más arcaicas de la psique. Cuando Jung declara que el hombre civilizado arrastra todavía tras sí la cola de un saurio, fija la imagen infernal de esta región ancestral del individuo que gobierna este planeta, descubierto el 21 de enero de 1930. Es el teclado de las tendencias afectivas con las fuerzas del mal: lo negro, lo feo, lo sucio, lo malo, lo revuelto, la angustia, lo absurdo, la nada, la muerte ...

\subsection{Emblemas y atributos}

En los sacrificios se le ofrecían a Hades ovejas y moruecos de color negro, color de luto y de los infiernos. La oveja es un animal de sacrificio: blanca, para los dioses celestes (del cielo) y negra, para las deidades subterráneas, como en el caso de Hades. 
El morueco es símbolo de la fuerza y fecundidad. Por ejemplo, entre los dogo (en una isla japonesa), el morueco ocupa la función de una divinidad agraria. En Egipto también observamos ese rasgo:

En ellos [los moruecos] residían las fuerzas que aseguraban la reproducción de los vivos; sus cuernos entraban en la composición de varias coronas mágicas, propias de los dioses y los reyes; eran el símbolo mismo del terror que irradia de lo sobrenatural (Chevalier 1982: 728) (La traducción es nuestra).

El proceso agrario está vinculado con la tierra y con la luna, que regula los ritmos propios del ciclo vegetal. Por tanto, el morueco es un animal selénico-telúrico.

Su fuerza de penetración es ambivalente: puede fertilizar o destruir (coincidencia de los opuestos) y esto es justamente lo que Hades manifiesta.

Hemos definido al morueco como animal lunar, pero Ad de Vries (1984: 380) afirma que es solar, como emblema del rey sagrado o el dios, rector de la fertilidad -característica también solar- y la resurrección. Así pues, como es costumbre cuando tratamos con seres míticos, el morueco revela una naturaleza solar y lunar a la vez. Cabe señalar que no es el azar quien dictamina cuáles son las víctimas para cada deidad: un animal que se sacrifica en honor a un dios guarda concomitancia con la naturaleza profunda del dios en cuestión.

Según el folklore sajón, el morueco es una forma que a menudo asume el demonio (igual que el macho cabrío). Por esta causa, las brujas lo montaban con placer.

El narciso le estaba especialmente consagrado. Esta flor está vinculada con los cultos infernales y ceremonias de iniciación, tales como los de Deméter en Eleusis. Hades lo lleva en ramillete, a la hora del rapto de Kore, es la flor de los muertos y sirve de preludio a la aparición del dios. Cosa curiosa: se plantaban narcisos sobre las tumbas en Grecia.

En griego, nárkissos, se relaciona etimológicamente con nárkee: entumecimiento, letargo, estupor. En este letargo se vislumbra el tránsito entre el mundo y el más allá, es decir, entre la vida y la muerte. Esta es, sin duda, una flor selénica, a partir de su rol fúnebre y su obvia calidad vegetal.

Entre los árboles, el ciprés le estaba ofrecido en su honor. Árbol mítico entre numerosos pueblos, para los griegos y romanos, está en relación con las divinidades del infierno: es el árbol de las regiones subterráneas, ligado al culto de Hades. Su resina incorruptible y su follaje persistente evocan la inmortalidad y la resurrección. En la China antigua, se consumían semillas de ciprés en procura de la longevidad. Ad de Vries nos indica varios rasgos del ciprés:

(...) life, fertility ... sky-deities... underworld-deities... death... sacred to underworld-deities... life after death, inmortality and resurrection; evergreen (Ad de Vries 1984: 125).

La granada está vinculada con el dios del infierno. Es un símbolo de fecundidad: en Grecia había un ritual, previo al matrimonio, de recolección de granadas, por parte de las mujeres y, en Roma, formaba parte del tocado de la novia. Hades le da unos granos de granada a Perséfone, con lo que ella se ata al mundo de los muertos para siempre. Así, por haberlos consumido, pasará un tercio del año en la oscuridad y los otros dos en el exterior. En Eleusis, los hierofantes iban coronados de ramas de granada durante los Misterios. En la mano de la 
diosa Hera es un símbolo de muerte y resurrección. Pausanias registra esta característica y añade un elemento enigmático:

La imagen de Hera está sentada en un trono (...) y en una mano sostiene una granada, en la otra un cetro. Lo que se refiere a la granada es algo absolutamente secreto, apártese de mi pluma (Pausanias 2, XVII, 4).

En una investigación precedente, habíamos anotado lo siguiente:

(...) la granada presenta un rasgo infernal y un aspecto integrador, matizados con el sesgo del tabú, sinónimo de lo sagrado, lo cual es vedado, prohibido, peligroso y, a la vez, extraordinario, grandioso y atrayente (Chinchilla 1989: 104).

Hades es un de los portadores de la cornucopia:

Hades'other name was Pluto, which in Greek means wealth, riches and the god's invisible fullness was symbolized by the image of the cornucopia that he held in his hands, overflowing with fruits and vegetables or with jewels, gems, gold and silver (Stassinopoulos, Arianna en Bolen 1989: 98).

El cuerno de la abundancia está relacionado con la figura de Zeus, pues uno de los cuernos de la cabra Amaltea, quien en otro tiempo lo nutriera, se había roto, sea por un designio, sea por el azar. Fue llenado con frutas y follaje. El joven dios lo otorga a las Ninfas como objeto milagroso, que les suministrará todo lo que pidiesen. Ovidio nos narra, de manera diferente, el origen de la cornucopia:

[la cabra Amaltea] (...) poseía unos cuernos levantados al aire y curvados hacia sus espaldas, y sus ubres eran las que hubiera podido tener una nodriza de Júpiter. Era esta cabra la que proporcionaba leche al dios. Pero un día se rompió uno de sus cuernos al chocar contra un árbol, y desde entonces se mostraba privada de la mitad de su belleza. La ninfa recogió el cuerno, lo adornó con hierbas recién cortadas y, lleno de frutas, lo acercó a la boca de Júpiter (Ovidio 1984: $341 ; \mathrm{V}, 155$ y ss.).

Otras versiones indican que Hércules, vencedor de Aqueloo, quien se había transformado en toro, le arranca uno de sus cuernos y se lo da a las Ninfas, quienes lo llenan de frutas, o bien a Eneo, padre de Deyanira, pues por ella había combatido con el dios río. Pero se presenta una confusión en cuanto al cuerno que le otorga el héroe: unos dicen que le regaló el cuerno de Amaltea, de la que habíamos hablado antes, y otros aseveran que el cuerno maravilloso es del propio Aqueloo:

[habla Aqueloo] (...) recurrí a transformarme en toro ... El intrépido héroe me agarró por los cuernos derribándome y quedándose con uno en sus manos. Las Náyades lo recogieron, llenándolo de flores y frutos, dando origen esto al cuerno de la abundancia... (Ovidio 1969: 220; IX, 85-8).

Diodoro Sículo apunta que Hércules entregó el cuerno a los habitantes de Etolia como símbolo de la fertilidad del país. Una leyenda menos propagada dice que el héroe lo habría recibido por parte de Hermes, al combatir contra Gerión.

Las leyendas del cuerno de Amaltea y del cuerno de Aqueloo son probablemente distintos en su origen, pero más tarde se les ha confundido para aseverar que el cuerno de la cabra era el mismo que el del río. Diodoro se basa en una etimología fantástica e inexacta que 
compararía "Amaltheia" con el nombre "amalakistía" (firmeza), característica de la fuerza invisible de Hércules.

Ateneo menciona que los cuernos de toro sirven como vasos para beber, con lo que se da origen al rython. Se mezcla el rython con el cuerno de la abundancia, pese a que son objetos diferentes; uno ha conservado su aspecto primitivo como utensilio doméstico y el otro, llega a ser un símbolo de la fertilidad y la abundancia.

El cuerno siempre tuvo un aspecto grande, lleno de frutas y follajes que guarnecen la abertura. Simbólicamente representa la nutrición para el hombre:

On a remarqué fort justement que cet assemblage de la corne à boire avec les fruits a dû exprimer de très bonne heure l'idée de bien-être et richesse, à une epoque où la boisson et les fruits de la terre suffissaient à la nourriture esssentielle de l'homme (Dict. des antiquitées..., vol. II, 1908-1929: 1515).

El cuerno es atributo de muchas deidades, entre ellas Plutón o Hades. El dios no es solamente la divinidad que destruye y aniquila: es quien se enriquece de todos los bienes que le son dados a los mortales y que, finalmente, vuelven a sus manos. El filósofo Cornutus dice que ha sido así llamado pues todas las cosas perecen, no hay nada que no vuelva a él y no llegue a ser su bien. La más interesante representación de este dios, con el cuerno de la abundancia, se halla sobre una copa del Museo Británico: muestra a los dioses reunidos en un banquete, Plutón ocupa el centro de la composición, extendido en reposo sobre un lecho, en frente de él aparece Perséfone sentada. El dios sostiene en una mano un phíalo (especie de vasija, similar a un plato), en la otra un largo cuerno de la abundancia. Pese a que el cuerno está vacío no hay duda de que se trata de la cornucopia. En la pintura de un ánfora de Nola, el objeto en cuestión aparece lleno de frutas y el dios lo lanza para raptar a Kore.

El cuerno de la abundancia es atributo de varios seres míticos: Baco, el Nilo, el Tíber (recuerdos de la leyenda de Aqueloo), la Fortuna, la Abundancia, la Paz, la Felicidad, la Concordia, la Esperanza, Vesta, Atys, Serapis, Isis, entre otros.

La cornucopia es un símbolo de la fecundidad y de la dicha: la profusión gratuita de los dones. Chevalier nos indica la evolución del símbolo:

En el transcurso del tiempo el cuerno de la abundancia se ha convertido en atributo, más bien que en símbolo, de la liberalidad, la felicidad pública, la ocasión afortunada, la diligencia y la prudencia que están en las fuentes de la abundancia, la esperanza y la caridad, la estación otoñal de los frutos, la equidad y la hospitalidad (Chevalier 1982: 347).

Regido por la coincidencia de los contrarios, es una combinación del falo y la vulva, como lo dice Ad de Vries (1984: 112):

(...) a combination of the strong phallic outside, and the vulva inside: androgyne as life and fertility symbol.

\subsection{Lugares de culto}

El horror que inspira el dios de los muertos basta para comprender que no fuera objeto popular de culto. Eustaquio tal vez exagera al decir que no había altar ninguno para él. Pero Pausanias nos cuenta que, en Pilos, los habitantes de Elide elevaron un templo al dios infernal, pues los auxilió y protegió del héroe invasor Hércules: 


\begin{abstract}
El recinto sagrado de Hades y el templo (pues tienen los eleos un templo y un santuario de Hades) se abren una vez al año y a nadie le es permitido entrar en ellos sino al sacerdote. De entre todos los hombres sólo los eleos que sepamos veneran a Hades y por la causa siguiente: cuando Hércules se dirigió contra Pilos de Elide dicen que Atenea les ayudaba y se cuenta que Hades vino en socorro de los de Pilos por odio a Heracles, pues tenía culto en Pilos (...) Creo que sólo lo abren una vez al año porque sólo una vez tienen entrada los hombres al Hades (Pausanias 6, XXV, 2-4).
\end{abstract}

\title{
3. Hades-Tezcatlipoca, la zona crepuscular, el reino funesto y mortuorio
}

Hades era también el nombre del reino de los muertos. El mundo inferior parece haber estado en la región en que se oculta el sol, más allá del río Océano que circunda la tierra. Otras veces, se le situaba en las entrañas de la tierra y se decía que podía penetrarse en él por algunas grutas o cavernas.

Hades evoca no sólo el reino de los muertos sino las riquezas subterráneas: el lugar de donde surge el mundo vegetal, pletórico de energía vital. He aquí, nuevamente, la coincidencia de los contrarios: vida muerte en el inframundo, lo subterráneo es el lugar de los ricos yacimientos, de las metamorfosis (rasgo lunar), de los pasos de la muerte a la vida, de la germinación.

Su nombre y sus rasgos se transfieren a esta zona: lugar invisible, sin salida, perdido en las tinieblas y el frío, frecuentado por monstruos y demonios atormentadores. Los griegos consideraban gélida esta región, al igual que los aztecas (cfr. con Niflheim, tierra fría y mortuoria del norte, en la mitología germánica).

En la tradición cristiana, la pareja luz-tinieblas simboliza los dos opuestos, el cielo y el infierno. Plutarco describía ya el Tártaro como privado de luz. Si la luz se identifica con la vida y con Dios, el infierno significa, pues, la privación de Dios y de la vida.

En el Nuevo Testamento, el infierno es el lugar propio de Satanás, figura que también nos interesa, asimilado con el fuego y el juicio final:

Apartaos de mí, malditos, al fuego eterno que está preparado para el diablo y sus ángeles (Mateo 25,41 ) (vid. Mateo 18, 9; 4, 29).

Dios no perdonó a los ángeles que pecaron sino que, precipitándolos en el abismo en cavernas tenebrosas, los entregó para ser custodiados para el juicio (2 Pedro 2,4$)$.

Y el diablo que los había seducido fue arrojado al lago de fuego y azufre, donde están también la bestia y el falso profeta; y serán atormentados día y noche por los siglos de los siglos (Apocalipsis 20,10).

Evidentemente, asociado al mal, todos sus "legionarios" vivirán eternamente en ese infierno, por una parte, oscuro ("caverna tenebrosa") y, por otro lado, ardiente ("lago de fuego y azufre"):

Pero la parte de los cobardes, incrédulos, culpables de abominaciones, homicidas, fornicarios, hechiceros, idólatras y de todos los embusteros, será en el lago que arde con fuego y azufre. Esta es la segunda muerte (Apocalipsis 21, 8).

En el Apocalipsis 6, 8 y en los apócrifos del Nuevo Testamento, el binomio HadesTezcatlipoca es la personificación del mundo inferior y, como ente mítico, es considerado malo y demoníaco relacionado con la muerte: 
El mar dio los muertos que en ellos estaban; y fueron juzgados cada uno según sus obras. Y la muerte y el Hades fueron precipitados en el lago. Esta es la segunda muerte: el lago de fuego (Apocalipsis 20, 13 y 14).

Psicológicamente decimos que hay un infierno en nosotros, una zona oscura que reprimimos y tememos:

(...) el infierno es el estado de la psique que ha sucumbido a los monstruos en su lucha, sea que haya probado de rechazarlos a lo inconsciente, o haya aceptado identificarse con ellos por una perversión consciente (Chevalier 1982: 592) (La traducción es nuestra).

Hades is the god presiding over out descents, investing the darkness in our lives, our depressions, our anxieties, our emotional uphealvals and our grief with the power to bring illumination an renewal (Stassinopoulos, Arianna en Bolen 1989: 98).

Tanto al descender al reino de Hades (catábasis) o al identificarse con el dios azteca nos damos cuenta de las riquezas que hay allí. Luego de vencer la oscuridad, encontramos la opulencia. Cuando la gente cae en la depresión profunda, se separa de la realidad ordinaria y es incapaz de sentir y llevar un "rayo de luz" a su vida diaria.

La "muerte" de un propósito, de un deseo, es una pequeña muerte que nos lleva al Hades, sea la zona oscura. Como Aquiles en Troya, el héroe, cuyo ego y valor es identificado con el éxito, quien puede perecer por la mayor derrota en el campo de batalla. Esto se traduce en un estado oscuro y tenebroso, propio del Hades.

Es el reino de lo inconsciente personal y colectivo. Tenemos pensamientos y sentimientos que reprimimos, cualquier cosa demasiado dolorosa, demasiado vergonzosa o inaceptable para los otros, lo que no se permite permanecer visible en el mundo exterior, anhelos que jamás incorporamos. En el mundo "subterráneo" de lo inconsciente colectivo existe cualquier cosa posible de imaginar. Este es el reino que tal vez obligó a decir a Terencio: Creo que nada de lo humano me es ajeno. Allí, en esta zona profunda de la psique, los arquetipos se manifiestan de formas diversas, todas simbólicas; son huellas profundas y arcaicas, comunes al hombre de todos los tiempos y expresas en los mitos o figuras míticas: Hades, Diónisos, Perséfone... Mientras nos identificamos con Zeus y los dioses del cielo (el bien, representado por Quetzalcóatl para los aztecas y Dios para los cristianos), el mundo subterráneo quedará como un lugar tremendo, lleno de riquezas ocultas, que podríamos encontrar.

Así, todo lo que necesitamos para sentirnos completos existe en el Hades. Esto es lo que Jung llama equilibrio psíquico, cuando ya no le tenemos miedo a la zona tenebrosa y vencemos los monstruos que allí habitan. Asimilado a lo inconsciente colectivo, las sombras del Hades son como los arquetipos, formas que requieren de la energía vital (recordemos cómo en la Odisea las almas del reino inferior necesitan beber la sangre de los sacrificios para poder "recordar").

Volviendo al dios heleno y al azteca, son deidades lunares, con rasgos solares: dadores de bienes, pero destructores a la vez, jueces de los muertos, reyes de la zona donde se conjugan la vida y la muerte (los ritmos o ciclos vitales), en suma, el mundo ctónico:

When the moon is dark, the god has done to the underworld, but he will surely return. His relation to human beings changes with his changing phases. In his uppre-world phase he is invariably beneficent, having the attributes of truth, justice, constructivensses and fertility [cuando porta la cornucopia]. In his underworld phase, however, he is destructive to earth dweller... he is the judge of the dead and the mediator between man and the gods... (Harding 1971: 91). 


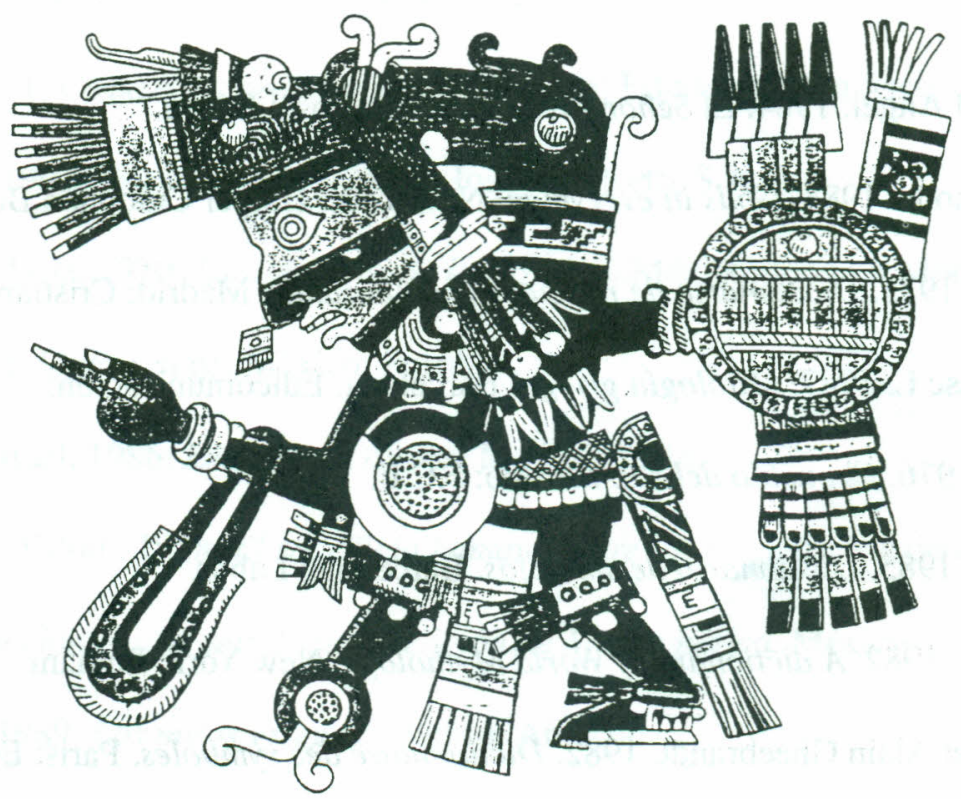

Fig. 1: Tezcatlipoca. Extraído de Caso, Alfonso, El pueblo del sol, pág. 10 (vid. Bibliografía).

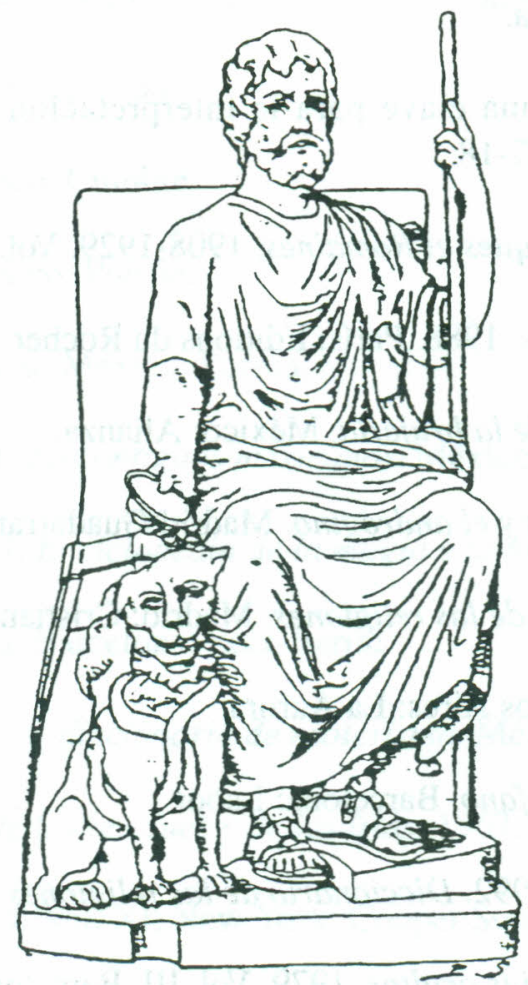

Fig. 2: $\quad$ Plutón. Pieza 5716 de la colección de la villa Borghese (Pompeya). Extraído del Dictionnaaire des antiquitées Grecque et Romaines, vol. X, pág. 517 (vid. Bibliografía). 


\section{Bibliografía}

Asturias, Miguel Ángel. 1984. El Señor Presidente. San José: Educa.

Bolen, Jean Shinoda. 1984. Gods in everyman. New York: Harper Colophon Books.

Brandon, S.G.F. 1975. Diccionario de religiones comparadas. Madrid: Cristiandad.

Cardona, Francesc L. 1987. Mitología griega. Barcelona: Edicomunicación.

Caso, Alfonso. 1976. El pueblo del sol. México: F.C.E.

Cirlot, Eduardo. 1985. Diccionario de símbolos. Barcelona: Labor.

Cotterell, Arthur. 1982. A dictionary of World Mythology. New York: Putnam.

Chevalier, Jean et Alain Gheebrandt. 1982. Dictionnaire des symboles. Paris: Editions Jupiter.

Chinchilla Sánchez, Kattia. 1989. El binomio indisoluble Deméter-Perséfone: integración mítico-simbólica de dos deidades selénico-telúrico-vegetales. Tesis de Licenciatura: Universidad de Costa Rica.

1992. "Mircea Eliade, una clave para la interpretación del pensamiento mítico". Revista Káñina. 25(1): 207-18.

Dictionnaire des antiquitées Grecques et Romaines. 1908-1929. Vol. 10. Paris: Hachette.

Dictionnaire des mythes littéraires. 1988. París: Editions du Rocher.

Donovan, Frank. 1989. Historia de la brujería. México: Alianza.

Eliade, Mircea. 1969. Mefistófeles y el andrógino. Madrid:Guadarrama.

1981. Tratado de historia de las religiones. Madrid: Cristiandad.

1984. La búsqueda. Buenos Aires: La Aurora.

1985. Lo sagrado y lo profano. Barcelona: Labor

Eliade, Mircea y Joan Couliano. 1992. Diccionario de las religiones. Barcelona: Paidós.

Enciclopedia Planeta de las ciencias ocultas. 1979. Vol. III. Barcelona: Planeta. 
Esquilo. 1980. Las siete tragedias. México: Porrúa.

Ferrero, Luis. 1981. Costa Rica precolombina. San José: Editorial Costa Rica.

Fuentes, Carlos. 1992. Terra Nostra. México: Joaquín Mortiz S.A.

Garibay, Angel María. 1970. La literatura de los aztecas. México: Joaquín Mortiz. 1980. Mitología griega. México: Porrúa.

Gómez Pérez, Rafael. 1986. Los nuevos dioses. Madrid: Rialp.

González Torres, Yoloth. 1988. El sacrificio humano entre los mexicas. México: F.C.E. 1991. Diccionario de mitología y religión de Mesoamérica. México: Larousse.

Graves, Robert. 1989. Los mitos griegos. Madrid: Alianza.

Grimal, Pierre. 1984. Diccionario de mitología griega y romana. Barcelona: Paidós.

Harding, María Esther. 1971. Woman's mysteries. New York: Harper Colophon Books. Himnos órficos. 1981. México: Porrúa.

Homero. 1978. Ilíada. México: Cumbre.

Homero. 1980. Odisea. México: Porrúa.

Horacio. 1986. Odas y épodos. México: Porrúa.

León-Portilla, Miguel. 1961. Los antiguos mexicanos. México: F.C.E.

María, Constantino de. 1984. Enciclopedia de la magia y la brujería. Barcelona: De Vecchi. Mármol, José. 1980. Amalia. Barcelona: Seix-Barral.

Masson, Hervé, 1975. Manual-diccionario de esoterismo. México: Roca.

Mitologías de las estepas, de los bosques y de las islas. 1967. París: Larousse.

Mythology of all races. 1964. Vol. XI. New York: Cooper Square Publishers.

Ovidio. 1969. Metamorfosis. Barcelona: Iberia. 
Ovidio. 1984. Fastos. Madrid: Editora Nacional.

Pausanias. 1986. Descripción de Grecia. Barcelona: Orbis.

Pike, Edgar R. 1991. Diccionario de religiones. México: F.C.E.

Sagrada Biblia. 1958. New York: Grolier.

Sahagún, Fray Bernardino de. 1956. Historia general de las cosas de Nueva España. México: Porrúa.

Sófocles. 1980. Las siete tragedias. México: Porrúa.

Soustelle, Jacques, 1984. La vida cotidiana de los aztecas en vísperas de la conquista. México: F.C.E.

Von Mayer, Peggy. 1989. "El sol en la mitología azteca”. Revista Káñina. 13 (1-2):157-63.

Vries, Ad de. 1984. Dictionary of symbols and imagery. Netherlands: Elsevier Science Publishing. 